\title{
EFFECT OF ATTACHMENT HEIGHT ON CHEWING EFFICIENCY FOR MANDIBULAR OVER DENTURE WEARER
}

\author{
Hala Mohamed Abd El Hameed*
}

\begin{abstract}
Purpose: The intent of this research was to study the effect of attachment height on chewing efficiency of the patients wearing mandibular overdenture

Materials and methods: Twelve male patients had completely edentulous maxillary and mandibular ridges, were elected to perform this study. All Patients received complete maxillary denture and mandibular over denture retained by two implants with locator abutments divided into two equal groups according to the length of the locator attachment.
\end{abstract}

GroupI: the patients were received locator abutment with $1 \mathrm{~mm}$ in height.

Group II: the patients were received locator abutment with $3 \mathrm{~mm}$ in height

Colored chewing gum used for estimation of chewing efficiency of the patients by the help of special software programs. The data was reordered and statistically analyzed at( two, four \&six) weeks from over denture insertion .

Results: between groups the results of this study reveled that Group II representing higher means of Delta E values than group I throughout different follow-up periods. These values were statistically significant at four and six weeks from over denture insertion at $\mathrm{p} \leq 0.05$.Within groups the results of this study presented that the means of Delta E values for group I\& group II increase throughout different follow-up periods. These values were statistically non significant at all observation periods for group I and statistically significant for group II at $\mathrm{p} \leq 0.05$.

Conclusion: Within the restrictions of this study it could be concluded that, the attachment height affects chewing efficiency of the patient.

\section{INTRODUCTION}

Complete edentulism is a multi-factorial issue that results from integration of cultural, attitudinal determinants, and preceding treatments. The state of complete edentulism proclaims a compromise in the masticatory system perfection accompanied by retrograde functional and cosmetic sequelae. ${ }^{I}$

As a result of teeth loss, the biting force downs from 200 psi. to 50 psi., with ulterior decrease in the masticatory function, which induce an increase

\footnotetext{
* Associate Professor of Prosthodontics, Faculty of Dentistry Suez Canal University
} 
in gastro-intestinal troubles. The end result is an extensive affection of the masticatory function, speech, esthetics, and the physiological well-being of the individual. ${ }^{2}$

Implementing patient satisfaction, within the biomechanical restraint, is the highest purpose in dental profession. The greatest wish of any edentulous patient is always fast, painless, and persistent missing teeth replacement together with the donation of a comfortable and firm prosthesis. ${ }^{3}$

Bite forces are markedly decreased in complete denture wearers comparing with natural dentate persons. Dentate people tend to provoke functional energy through food bolus, whereas complete denture wearers have most of their chewing capacity distributed outside the bolus, via the denture base to the supporting tissues. ${ }^{4}$

Despite of using complete dentures as a treatment preference of complete edentulism has already proven its priority, yet prosthodontics are playing a significant role to offer treatment facilities that can solve the problems of inferior retention and diminished stability of dentures mainly for mandibular one, which have been stamp out by institution of dental implants. ${ }^{5}$

The implant supported over dentures presented a valid treatment modality, that providing phonetic and esthetic advantage. It yields better chewing awareness, masticatory performance, less complaints and higher contentment when comparing to conventional complete denture ${ }^{6}$

Locator is a resilient stud attachment used with overdentures. It is a newer clinical alternate to the established attachments that was brought up in 2001. This attachment is self-aligning and has a distinctive characteristics of dual retention with combined internal and external retentive features. ${ }^{7}$

Masticatory performance is a serious parameter for objective estimation of the masticatory function and success of dental management. The valuation of the masticatory performance is beneficial for evaluating subject's functional ability and establishing treatment planning for rehabilitation of the diminished oral function. ${ }^{8}$

One of newly introduced methods for estimating masticatory ability is using chewing gum. Because of its simplicity, quickness, validity and reliability, this method can be used for evaluating masticatory performance by measuring changes in gum color. ${ }^{9}$

Many previous studies compared between locator attachment and another attachments. However, limited data were collected regarding the masticatory performance whenever using implant locators of different length to retain implant mandibular over dentures.

\section{MATERIAL AND METHODS}

Twelve male patients, their ages spread between 50-65 years old, with edentulous maxillary and mandibular ridges. They were elected from the outpatient clinic of the Department of Prosthodontics, Faculty of Dentistry, Suez Canal University. The chosen patients were aware of the nature of the research work. After achieving patient's approval, only co-operative patients were participated in the study.

After clinical and preoperative radiographic assessments, all patients were given conventional complete dentures . Two implants were integrated in the canine area by the help of CAD/CAM based surgical guides as follows:

\section{Scan appliance preparation:}

Duplication of lower denture for each patient was done using silicon putty consistency (Zetaplus. $\mathrm{C}$-silicone putty Italy) in a duplicating flask. A mix of the putty material was adapted to fill one part of the duplicating flask. The denture was embedded into soft mix to create an imprint for the fitting surface of the denture. 
A second mix of the material placed in the counterpart of the flask which was firmly closed to create an imprint of the polished and occlusal surface of the denture. After setting of the rubber base, the denture was removed. Radiopaque acrylic resin is prepared by mixing auto polymerizing acrylic resin with barium sulfate at a ratio of 3:1. The mix was applied into the mold and the container was firmly closed until complete setting of the resin. Small channels were prepared through the long axes of the teeth by medium size fissure bur. Stents were tried in the patient's mouth for fitness and stability (Fig 1A, 1B).

\section{Patient radiographic imaging:}

A vinyl polysiloxane (VPS) bite index was taken in the patient's mouth in centric relation. A preoperative CBCT scan was taken for the patient's maxillary and mandibular arches with the scan appliance and interocclusal bite index in their position in the patient's mouth with CBCT machine. The resultant image was obtained as data on a compact disc DICOM (digital imaging and communications in medicine).

\section{Virtual planning and surgical guide fabrication}

After CBCT scan, optical scanning of the cast was done producing an STL file which can be easily merged into the planning software. The models with the radiographic template fitted on it were scanned again using the optical scanner. ${ }^{10}$

Both scans were imported to the blue sky plane 3 software and were used together with the preoperative CBCT for ideal implant position planning. (Fig 1C) Two Implants were placed in sufficient bone locations guided by the radiolucent channels in the scan appliance at place of canine area. The two implants were planned parallel to each other. The final virtual surgical guide was then exported as STL (standard tessellation language) file and sent through an e-mail to the additive manufacturing machine for guide fabrication.$^{11}$

The 3D virtual stent was processed with special software at the rapid prototyping unit. Selective laser sintering technology was used to build the stent from poly-amide material (EOS 4 Mega selective laser melting machine. Germany). Metallic sleeves were then fitted into the planned holes of the fabricated stent (Fig 1D).

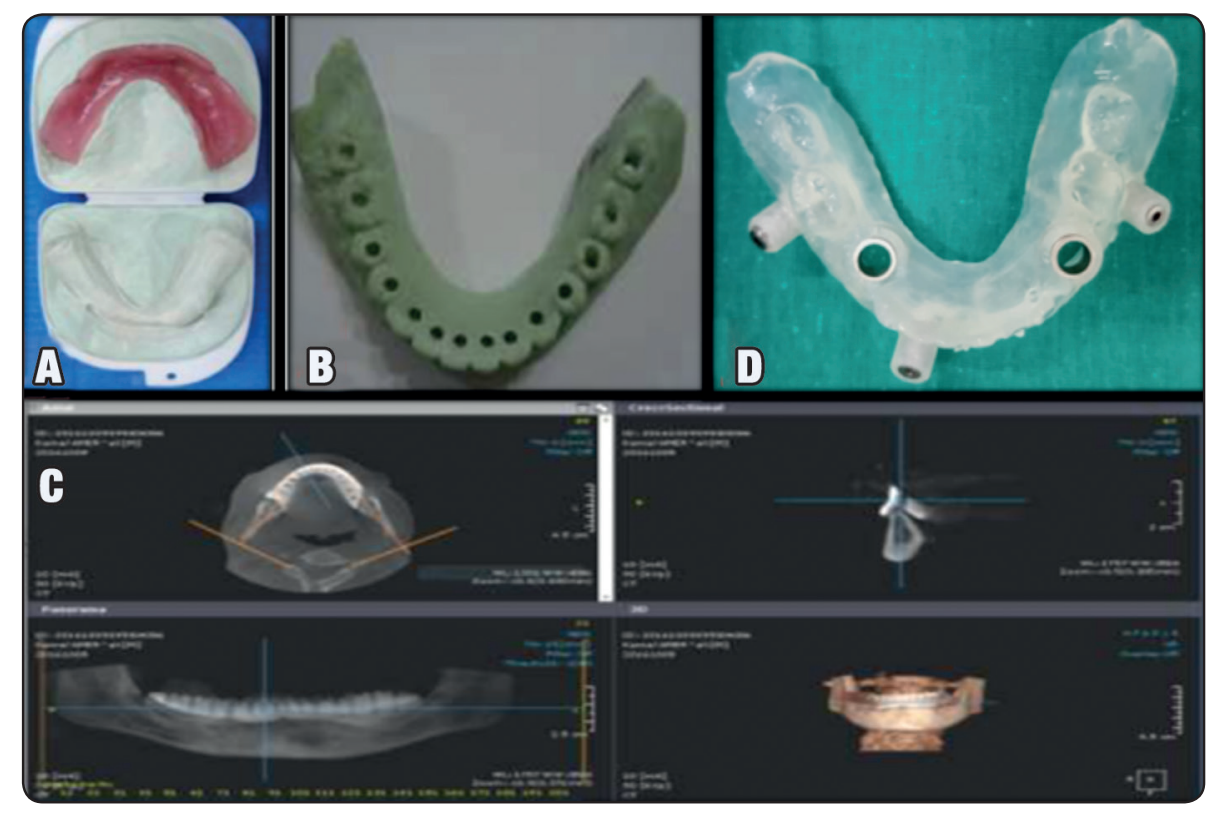

Fig. (1) A denture duplication, B scanning appliance, C cone beam with scanning appliance in patient mouth \& D computerized surgical stent 


\section{Surgical and Implant installation procedures}

Every patient received two root form, tapered threaded dental implants (S-clean tapered dental Implant fixtures - Dentis- Korea ), that were selected according to available bone width and length. The surgical stents were checked inside the patient's mouth for fitness and stability.

The surgical guide was firmly fixed to the underlying mucosa and bone by bite index and three fixation screws in a tripod position. After removal of the silicone bite, the fitness and adaptability of the surgical stent were checked. The flapless surgery was performed with computer guided surgical kit using pilot drill followed by two successive drills guided by the path initially created by the pilot drill. After this, the fixation screws and the surgical stent were removed to continue osteotomy preparation with final drill (from universal kit of dents)by free hand sequential drilling guided by the path initially created by the preceding drills(Fig 2A,2B).

The implant was inserted manually in the prepared osteotomy site by the help of its fixture mount. When manual tightening met resistance, further tightening via the ratchet was continued until reaching the required depth. The cover screw corresponding to the implant was then tightened in place by the hand driver.

The mandibular denture was relieved against the surgical site. And relined with a soft tissue conditioning material. Three months later and after accentuation of the osseointegration, the patient presented for receiving the attachment.

In each patient the cover screws were removed and the locator abutment were screwed in the internal hex of the implants using the insertion key for locator abutments and a torque wrench $(30 \mathrm{~N} /$ $\mathrm{cm})$ to achieve maximum seating force and prevent screw loosening.

Positioning of white spacer over the head of each locator abutment was done to block out the undercut areas surrounding the abutment during pick up procedure. The locator metal housing was placed into each locator abutment (Fig 2C,2D). The denture was relieved with two small holes were made on the lingual surface of the denture for escaping of excess acrylic material during the pick-up procedure. Self cure acrylic resin was put in the relieved areas. The denture was inserted and the patient was guided to occlude in centric relation, avoiding excessive pressure during setting time.

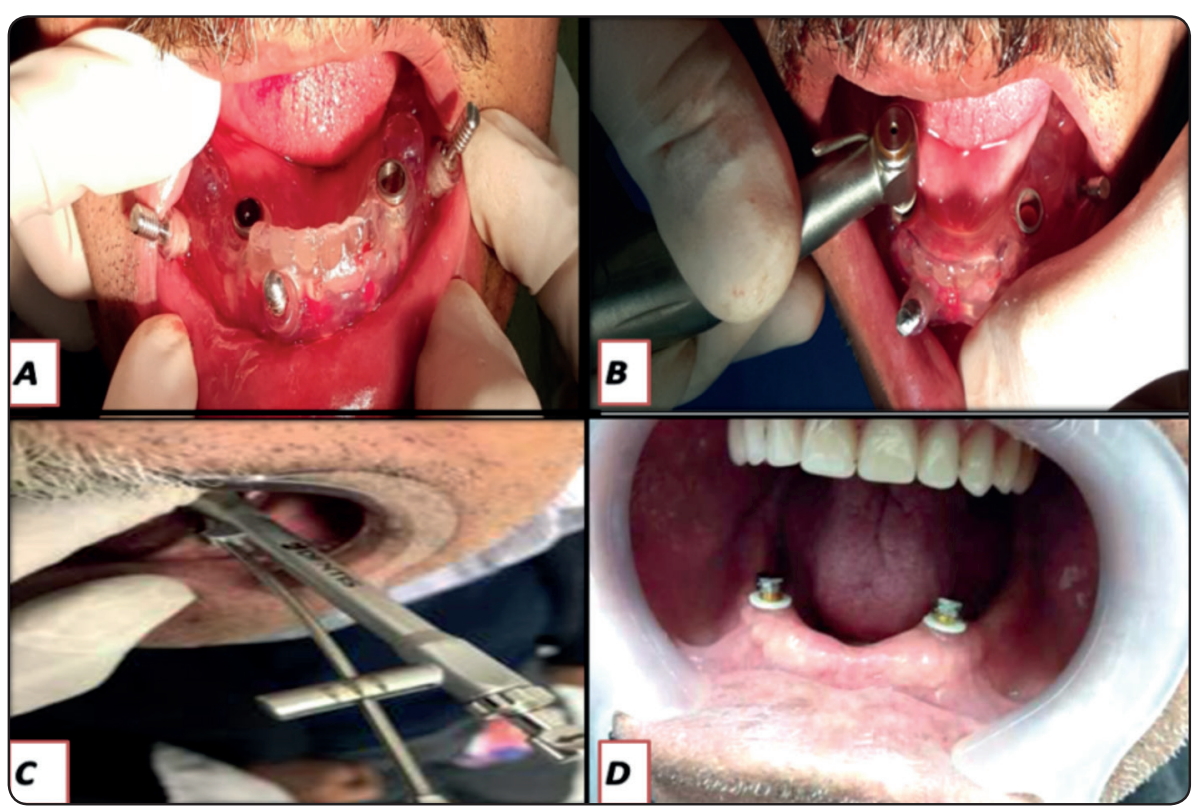

Fig. (2) installation of implants by computerized stent $(\mathrm{A}, \mathrm{B})$, locator abutment was tightened(C), locator denture cap was inserted into each locator abutment, leaving the white block-out spacer beneath it (D) 
After curing of the acrylic resin and removal of the denture, the white spacer was discarded followed by, removal of excess acrylic and denture polishing.

\section{Grouping of the patients:}

All Patients sharing in the study received complete maxillary denture and mandibular overdenture retained by two pieces implant with locator abutment divided into two equal groups according to the length of the locator attachment:

GroupI: the patients of this group were received locator abutment with $1 \mathrm{~mm}$ in height.

Group II: the patients were received locator abutment with $3 \mathrm{~mm}$ in height

\section{Measuring chewing efficiency:}

Before chewing test each patient was asked to clean his denture well and rinse his mouth with cold water. A coloured chewing gum "Trident,Turkey ، with strawberry or watermelon flavor, each specimen was in dimension of $(30 \times 10 \times 3 \mathrm{~mm})$ used for this study. Each patient was asked to chew two samples of gum for 20 strokes on both right and left sides respectively, with 15 minutes imposed between them to reduce the effect of fatigue ,this provides 12 samples for each group for better statistical analysis. The chewing cycles were counted by observing the movement of the mandible in the anterior plane and evaluating the up-and-down movements. The specimens were retrieved from the oral cavity, and excess saliva was removed with a cotton roll or dental air water spray, after that the chewed gum delivered into a plastic sheet. Samples before and after chewing were photographed using professional digital camera (resolution 300 dpi, Epson Perfection V750 Pro, Seiko Epson Corp., Japan). The images were imported to a freely available application(color analysis professional software). The image has been processed by the software to get the color information :RGB, Hex code,color name and group) fig.3A.
These specimens were compared with non chewed gums that served as baseline. RGB or Hex code information for each specimen - before and after chewing - was introduced manually to another software application (Nix Pro color sensor application) that compare between them representing the change in the color of the chewed gum by Delta $\mathrm{E}$ valuesfig.3B (the greater $\boldsymbol{\Delta} \boldsymbol{E}$ values the greater chewing efficiency). These Delta E values for all samples of both before and after chewing were collected for statistical analysis at two, four \&six) weeks from denture insertion .

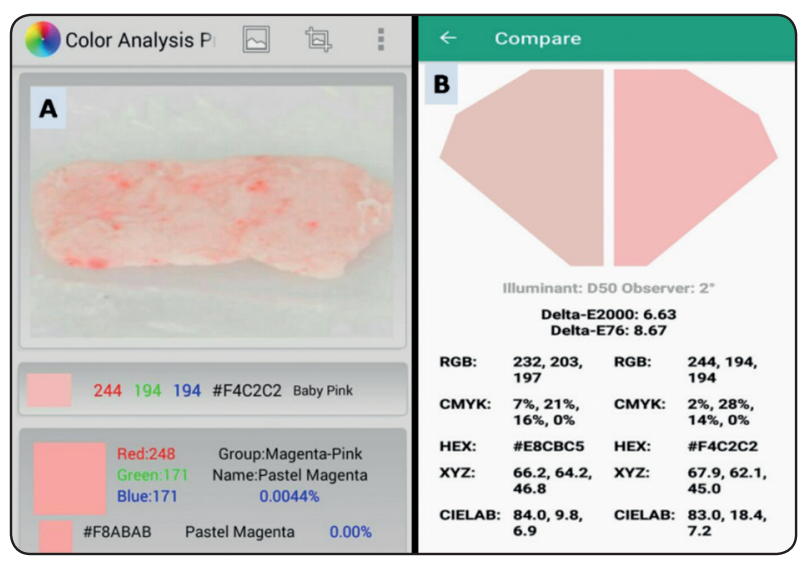

Fig (3) A\&B colorimetric analysis for the chewing gum using special software programs

\section{RESULTS}

The change in the color values $(\boldsymbol{R G B}$ or $\boldsymbol{H e x}$ code information) of the chewed gum represented by Delta $\mathrm{E}_{2000}$ values. Data were presented as means and standard deviation. Paired t-test was used to compare the mean values of Delta $\mathrm{E}$ for all samples between both groups ,that were calculated throughout different follow-up periods.

The significance level was set at $\mathrm{p} \leq 0.05$ and highly significant at $\mathrm{p} \leq 0.001$.

I-Between both groups : From Table (1)and Fig.4 there were changes in color values of the chewed gum samples for both groups. 
Group II (locator abutment of higher length) representing higher means of Delta $E$ values than group I throughout different follow-up periods. These values were statistically significant at four and six weeks from over denture insertion at $\mathrm{p} \leq 0.05$, as $(\mathrm{p}=0.03 \& 0.016)$ respectively and statistically non significant at two week from over denture insertion as $(\mathrm{p}=0.08)$.

TABLE (1) shows the mean of Delta E values between both groups throughout different follow-up periods

\begin{tabular}{|c|c|c|c|c|}
\hline Intervals & & 2 Week & 4 Week & 6 Week \\
\hline Groups & & & & \\
\hline G I & Mean \pm SD & $6.771 \pm 0.52$ & $7.143 \pm 0.53$ & $7.243 \pm 0.464$ \\
\hline G II & Mean \pm SD & $7.329 \pm 0.55$ & $7.886 \pm 0.612$ & $8.114 \pm 0.661$ \\
\hline & $\mathrm{P}$ & 0.08 & $0.03^{*}$ & $0.016^{*}$ \\
\hline & $\mathrm{t}$ & -1.933 & -2.418 & -2.85 \\
\hline
\end{tabular}

$S D=$ Standard deviation *significant at $p \leq 0.05$

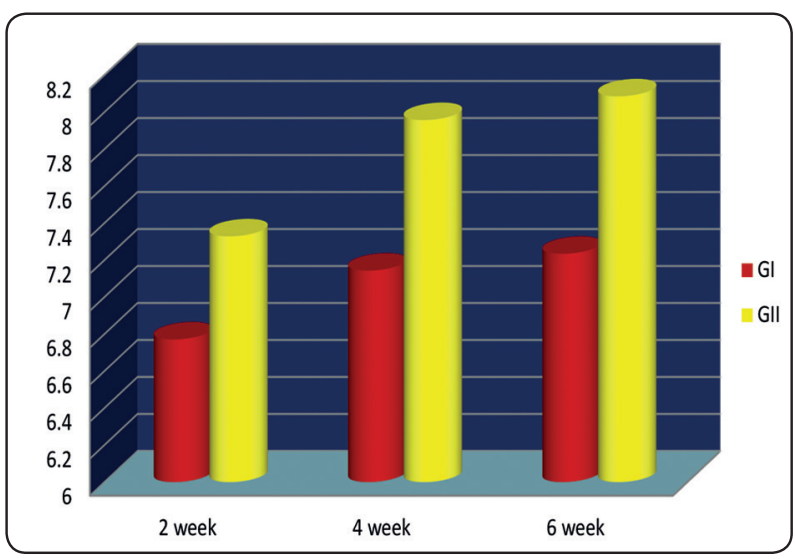

Fig. (4) Mean Delta E values between both groups

\section{II- within each group :}

One-way analysis of variance (ANOVA) at $95 \%$ confidence level was used to examine variable effects within each group. Turkey's post-hoc test for pair -wise for comparison was used when ANOVA test yielded significant difference between groups.
From Table (2)and Fig.5A, for Group I the means of Delta $\mathrm{E}$ values increase throughout different follow-up periods. These values were statistically non significant at all observation periods from over denture insertion at $\mathrm{p} \leq 0.05$, as $(\mathrm{p}=0.218)$

From Table (3)and Fig.5B, for Group II the means of Delta $\mathrm{E}$ values increase throughout different follow-up periods. These values were statistically significant at all or some observation periods from over denture insertion at $\mathrm{p} \leq 0.05$, as $(\mathrm{p}=0.05)$.

By comparison test there were significant difference between ( 2 week \& 4week) as $\mathrm{P} 1=$ 0.043 and also between (2week\& 6week) follow up periods, as $\mathrm{P} 3=0.013$,while there was non significant difference between (4week\& 6week) follow up periods as $\mathrm{P} 2=0.241$

TABLE (2) Shows the mean of Delta E values within GI throughout different follow-up periods

\begin{tabular}{|c|c|c|c|c|}
\hline Intervals & mean & SD & P-value & F \\
\cline { 1 - 3 } 2 weeks & 6.771 & 0.52 & & \multirow{2}{*}{0.218299} \\
\cline { 1 - 2 } 4 weeks & 7.143 & 0.53 & & \\
\hline 6 weeks & 7.243 & 0.612 & & \\
\hline
\end{tabular}

TABLE (3) Shows the mean of Delta E values within GII throughout different follow-up periodsFig $5 \mathrm{~A} \& \mathrm{~B}$ mean Delta $\mathrm{E}$ values within each group.

\begin{tabular}{|c|c|c|c|c|c|c|c|}
\hline Intervals & Mean & SD & F & P-value & P1 & P2 & P3 \\
\cline { 1 - 3 } 2 weeks & 7.329 & 0.55 & & & & & \\
\cline { 1 - 3 } 4 weeks & 7.886 & 0.612 & 3.4234 & $0.05^{*}$ & $0.043^{*}$ & 0.241 & $0.013^{*}$ \\
\cline { 1 - 3 } 6 weeks & 8.114 & 0.661 & & & & & \\
\hline
\end{tabular}




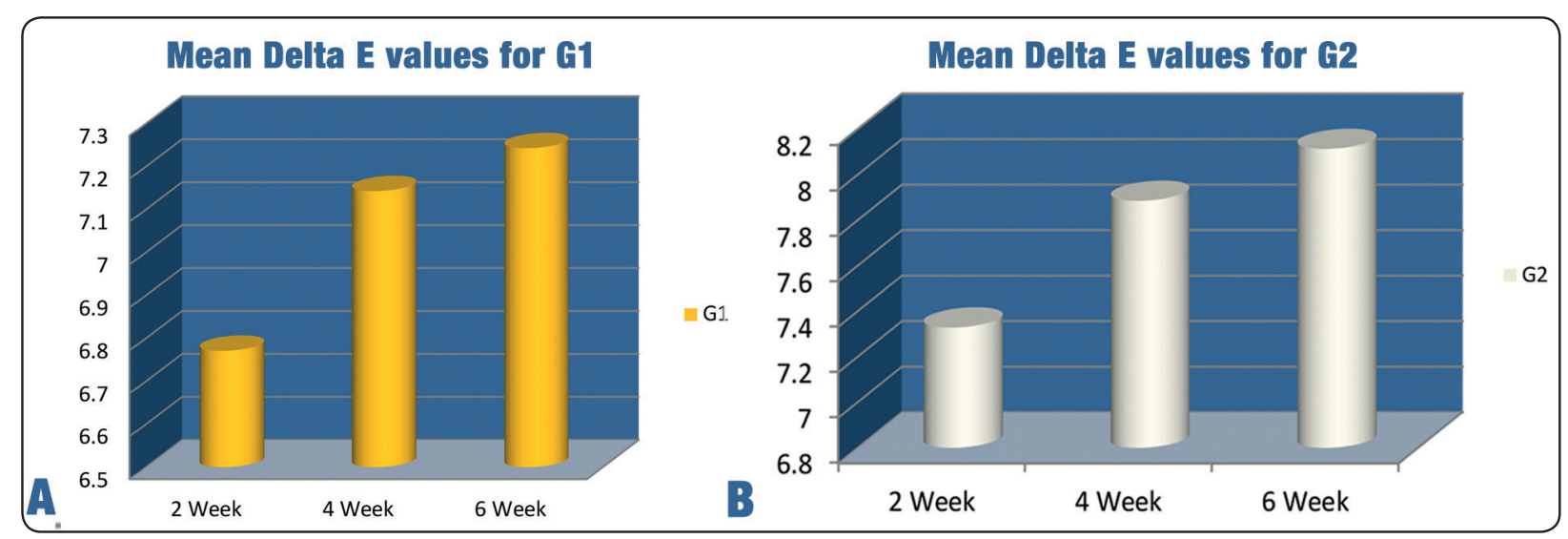

Fig (5) A \&B mean Delta E values within each group

\section{DISCUSSION}

The design of overdenture attachment system should provide optimal force distribution around supporting implants by transmission the occlusal forces in the direction of the implant long axes ,keeping the overdenture from dislodging for the patients to be capable of performing a normal, comfortable chewing function. ${ }^{12}$

Mandibular overdentures constructed to preclude most of the problems that occur with the mandibular conventional dentures, due to higher rate of bone resorption and lower surface area comparing to maxillary one as well as tongue movements that affect retention and stability of the mandibular denture consequently affects the chewing efficiency. ${ }^{13,14}$

The male patients were preferable to preclude the differences in muscle efficiency between both sexes. The considerations that participate in the preference of male selection, including hormonal alternations and psychological factors. Morever, elderly females showed a lower rate of chewing efficiency than males. ${ }^{15}$

After the introduction of cone beam computed tomography (CBCT), the precision of implant positioning has been increased as it provides a threedimensional (3D) view of anatomical structures.
Developing of various implant planningsoftware packages was done for virtually planning implant's positions in patients. The conclusions of different authors proposed that the fineness of implant positioning and the duration of implants are much greater than those done through the traditional method. ${ }^{16,17}$

Many benefits of computer-guided stent-based implant placement embracing, the preservation of soft tissues, prime utilization of available hard tissues, less invasive surgical approach and more surgical accuracy due to stent stabilization ${ }^{18}$

Locator attachment produce unique dual retention which provides a greater retention surface area than comparable to other types of attachments. It's a resilient, retentive, durable, also has some built-in angulations compensation. In addition, its repair and replacement are much easier and faster. It fulfills functional, social and economic expectation of patients with ease and gratification ${ }^{19}$

Using gum has some important priorities as many people are accustomed to use chewing gums, thus a more unconscious chewing has a great potential for occurrence. Furthermore, the test samples can be stored for many weeks, are ready available, not pricey and are offered in standardized quality. 
Color-mixing ability tests are most likely to supply clinical relevant information on chewing impairment and might be applied in geriatric or special care patients. Further simplification of the opto-electronical assessment might facilitate establishing widespread screening for chewing deficiencies. ${ }^{20}$

Colorimetric software analysis was accomplished for the samples because visual assessment seemed to be less reliable than digital image processing. Colorimetric analysis can confirm numerous parameters from the digital image as RGB, Hex code, HSL, HSV, color name and group. ${ }^{21}$

The grades of chewing cycle numbers $(\mathrm{n}=5$, $10,20,30,50)$ were elected to overlay the entire range of potential degrees of colour mixture which can be given from individuals with sorely impaired to a totally purposeful chewing performance. The analysis of the inter- and intra-individual reproducibility advised that for the test application a fixed number of 20 chewing cycles ought to be applied. This number of mastication cycles was ought to be helpful in most mixing-ability tests. In addition, it had been incontestable that the best corelation coefficient between a mixing-ability test and a comminuting test for masticatory efficiency is also at 20 chewing cycles. ${ }^{22}$

Increased chewing efficiency in group II than group I ,can be explained by the two crown height concerns with implant retained overdentures. The first crown height space is that from the superior of the attachment system to the bone crest, whereas the second crown height space is taken into account to be the distance from the top of the attachment to the occlusal plane.

Within the existing study, the first crown height space was designed to be one $\mathrm{mm}$ above gingiva in GI and three mm in GII. From this view point, the second crown height space was reduced one $\mathrm{mm}$ in GI and three $\mathrm{mm}$ in GII, respectively (i.e. second crown height is shorter by $2 \mathrm{~mm}$ in GII than GI). This thereby decreasing the lever arm (more denture stability and better chewing efficiency) for GII than GI .23,24

\section{CONCLUSION}

Within the restrictions of this study it conceivable achieving that, with proper denture construction, the attachment height affects denture stability and consequently chewing efficiency of the patient.

Certain recommendations about the attachment length in terms of their impacts on chewing efficiency cannot be drawn by two-lengths only for further researches of other lengths

\section{REFERENCES}

1. McCord J F: Risk management in clinical practice. Part 6a.Identifying and avoiding medico-legal risks in complete denture prosthetics. Br Dent J. 2010; 209: 273-276.

2. Goiato M, Garcia A, Santos D: Electromyographic evaluation of masseter and anterior temporalis muscles in resting position and during maximum tooth clenching of edentulous patients before and after new complete dentures. Acta Odontol. 2007;20:67-72 .

3. Lerner H:Minimal invasive implantology with small diameter implants. Implant Practice. 2009; 2: 30-35.

4. Deniz D, Ozkan Y:The influence of occlusion on masticatory performance and satisfaction in complete denture wearers. J Oral Rehabil .2013; 40:91-98.

5. Huard C, Bessadet M, Nicolas E: Geriatric slim implants for complete denture wearers: Clinical aspects and perspectives. Clin.Cosmet. Investig. Dent. 2013; 5: 63-68.

6. Bilt A, Burgers M, Kampen F, Cune MS :Mandibular implant-supported overdentures and oral function. Clin Oral Impl Res .2010;21:1209-1213.

7. Ghotmi M, Homsy F, Daou E : The Locator: Useful attachment for overdentures. A practical description. J L D A. 2013; 48: 69-74.

8. Silva LC, Nogueira T E, Rios LF, Schimmel M, Leles C $\mathrm{R}$ : Reliability of a two-colour chewing gum test to assess masticatory performance in complete denture wearers $\mathrm{J}$ Oral Rehabil. 2018;45:301-307.

9. Tarkowska A, Katzer L, Ahlers M O: Assessment of masticatory performance by means of a color-changeable chewing gum. J Prosthodont Research.2017;6: 9-19. 
10. Mora M A, Chenin D L, Arce, R M : Software tools and surgical guides in dental implant-guided surgery. Dental clinics of North America.2014;58:597-626 .

11. Nikzad S, Azari A.:A novel stereolithographic surgical guide template for planning treatment involving a mandibular dental implant. J Oral Maxillofac Surg. 2008; 66:1446-1454.

12. Minstry S, Ahuja S, Karani J, Bhatnagar V: Enhancing retention of overdentures with semi precision attachmentsA case series. J App Dent Med Sci. 2016;2:2-8.

13. Nissan J., Oz-Ari B., Gross O.: Long term prosthetic aftercare of direct versus indirect attachment incorporation techniques to mandibular implant supported overdenture. Clin. Oral Implants Res. 2011; 22: 627-630.

14. Lee C. K. and Aqar J. R.: Surgical and prosthetic planning for a two implant-retained mandibular overdenture: A clinical report. J Prosthet. Dent. 2006; 95: 102-105.

15. Pan S, Awad M, Thomson JM, Dufresne E, Kabayashi T, 53. Kimoto S, Wallin SD, Feine JS. Sex differences in denture satisfaction. J Dent. 2008, 36:301-308.

16. Gajjar C, Ajmera V, Shah D, Chauhan C, Doshi P. A Flapless surgical Placement of implants in mandibular arch using computer-guided surgical stent. J Advanced Oral Research 2018;9 : 55-60

17. Beretta M, Poli PP, Maiorana C. Accuracy of computeraided template-guided oral implant placement: a pro- spective clinical study. J Periodontal Implant Sci. 2014; 44:184-193.

18. Pawar A, Mittal S, Singh RP, Bakshi R, Sehga V. A step toward precision: a review on surgical guide templates for dental implants. Int J Sci Study. 2016;3:262-266.

19. Mahajan N. and Thakkur R. K.: Overdenture locator attachments for atrophic mandible. Contemp. Clin. Dent. 2013; 4: 509-511.

20. Schimmel M, Christou P, Miyazaki H, Halazonetis D, Herrmann F R, Mu“ller F. A novel colourimetric technique to assess chewing function using two-coloured specimens Validation and application. J Dent. 2015 ;43: 955-964

21. Van der Bilt A, Speksnijder C M, Deliz Pocztaruk R, Abbink J H. Digital image processing versus visual assessment of chewed two-color wax in mixing ability test. J Oral Rehabil. 2012;39: 11-17.

22. Kaya MS, Guclu B, Schimmel M, Akyuz S. Two-color chewing gum mixing ability test for evaluating masticatory performance in children with mixed dentition: validity and reliability study. J Oral Rehabil. 2017;44:827-834.

23. Ozan O, Ramoglu S. Effect of implant height differences on different attachment type and peri-implant bone in mandibular two-implant overdenture: 3D finite element study. J Oral Implantology.2015; 3:50e-59e.

24. Misch C. E.: Dental implant prosthodontics. $2^{\text {nd. }}$ ed: Mosby Inc.;2015. 